\title{
Showtime! Should an IACUC oversee companion animal exhibition activities on campus?
}

$\mathrm{O}$ ne of the most popular clubs on the Great Eastern University campus was the Canine and Feline Exhibition Club, better known as the CAFE club. The club was open to any Great Eastern student who wanted to exhibit their pet in a traditional dog or cat show, or dog agility competitions. There were weekly meetings of the club where animal grooming, show information, health, training, and related topics were discussed. As with many other clubs on campus, the CAFE club had a faculty advisor who would provide advice and help club members as needed. However, the CAFE club's advisor, Dr. Jeremy West, had an additional role in the club. West was very experienced at preparing and handling dogs and cats at regional and national shows and he often used his own or student animals to teach club members how to groom, train, and exhibit animals in shows.

In due time the Great Eastern IACUC office was informed about the activities of the CAFE club and asked if the club needed to have an IACUC protocol and approval for its animal training activities. The quick response from the office was no, these were privately-owned animals not used in any formal research or teaching, and therefore the IACUC did not need to become involved. But after some consideration, the director of the office began to have second thoughts. Dr. West was a university employee and the club met on university property. Although his teaching was not in a formal university course, there was no question that animals were being used in an informal teaching activity for university students. Still, the teaching activity was more geared toward exhibition purposes than research purposes, so the director was not sure if IACUC approval was or was not required.

What is your opinion? Why or why not would the CAFE club's activities need IACUC approval?

\section{Jerald Silverman}

University of Massachusetts Medical School,

Worcester, Massachusetts, USA.

e-mail: Jerald.Silverman@umassmed.edu

Published online: 19 February 2019

https://doi.org/10.1038/s41684-019-0239-4

\section{Knowing is half the battle}

W

e agree with the initial reaction of Great Eastern's IACUC. The activities of the CAFE club are

\section{A WORD FROM OLAW}

In response to the issues posed in this scenario, the National Institutes of Health Office of Laboratory Animal Welfare (NIH-OLAW) provide the following clarifications:

In this scenario, a university-supported club provides informal instruction on handling, grooming and training of pet dogs overseen by an experienced faculty advisor. The question raised is whether IACUC review and approval is required for these activities.

As noted by other reviewers, IACUC review of such informal activities is not a federal requirement because the animals are not undergoing manipulation for research or for training of medical or veterinary students ${ }^{1,2}$. However, some IACUC oversight is advisable to ensure animal and human safety and limit liability to the institution should a pet be injured accidentally or cause harm to the students or others. A consent agreement with animal owners developed with legal counsel may also be a consideration. A university policy or standard operating procedure for the club that addresses animal vaccinations, exempt from IACUC review because they do not include research or training of medical or veterinary students. That said, because

temperament, access to food and water, locations where animals are allowed, and how animals are to be restrained is a suggested approach. When the institution includes all animals regardless of the activities or funding source in the Assurance with OLAW, some form of IACUC oversight would be expected. However, there is flexibility in the use of policies or SOPs for non-research activities.

Patricia Brown

Director, OLAW, OER, OD, NIH, HHS.

e-mail:brownp@od.nih.gov

Published online: 19 February 2019 https://doi.org/10.1038/s41684-019-0243-8

References

1. Public Health Service. Policy on Humane Care and Use of Laboratory Animals - Frequently Asked Questions. Applicability of the PHS Policy, Question No. A.7. (US Department of Health and Human Services, Washington, DC, 2006, revised 2013); http://grants.nih.gov/grants/olaw/faqs.htm\#a7.

2. Public Health Service. Policy on Humane Care and Use of Laboratory Animals - Frequently Asked Questions. Protocol Review, Question No. D.8. (US Department of Health and Human Services, Washington, DC, 2006, revised 2013); http://grants.nih.gov/grants/olaw/faqs.htm\#proto_8. the club activities were brought forward, either by conscientious individuals who are involved in the club and want to ensure they are following all campus rules or by some outside entity who might have concerns about the club, the IACUC will need to respond definitively.

In cases of exempt activities at our institution, the IACUC can generate a "memo of exemption" upon request. This is a written notice that describes an activity and states that it is exempt from IACUC oversight, enabling participants in non-covered activities to receive a written assurance of compliance for their records.

In addition, our university has devised an IACUC process for on-campus extracurricular club activities. We use a protocol modification form, "Non-invasive, Non-painful Teaching Observations or Demonstrations." This is a simple form reviewed by designated member review, and it was created to reduce regulatory burden associated with noninvasive, non-painful veterinary teaching activities in routine coursework-for example, external palpation of anatomic landmarks during physical examination practice with student-owned dogs-under an approved "blanket" protocol. The form also has been used electively for club 